\title{
CERVICAL HUMAN PAPILLOMAVIRUS INFECTION IN ACCRA, GHANA
}

\author{
A. B. DOMFEH ${ }^{1}$, E. K. WIREDU, A. A. ADJEI, P. F. K. AYEH-KUMI, T. K. ADIKU, Y. TET- \\ TEY, R. K. GYASI and H. B. ARMAH \\ ${ }^{1}$ Department of Pathology, University of Pittsburgh Medical Center, Pittsburgh, Pennsylvania 15213, USA; \\ Department of Pathology and Department of Microbiology, University of Ghana Medical School, College of \\ Health Sciences, University of Ghana, Korle-Bu, Accra, Ghana.
}

\author{
Author for correspondence: Dr. Akosua B. Domfeh, \\ E-mail: domfehab@upmc.edu \\ Conflict of Interest: None declared
}

\begin{abstract}
SUMMARY
Background: This study was aimed at estimating the human papillomavirus (HPV) prevalence and its determinants among a sample of Ghanaian women.

Design: Cross-sectional observational study.

Setting: Gynaecology outpatient clinic of the Korle-Bu Teaching Hospital, Accra, Ghana; the largest tertiary care gynaecology outpatient clinic in Ghana.

Participants: Convenient sample of 75 consenting women visiting the clinic.

Methods: Information was obtained through personal interviews using structured questionnaire, Pap smears obtained, and laboratory testing of cervical exfoliated cells was performed. HPV DNA was detected using a GP5+/6+ polymerase chain reaction assay. These data were analyzed using both univariate and bivariate techniques.

Results: The mean age of participants was 33.3 years (standard deviation, 9.2) and the percentage of lifetime monogamy was $21.3 \%$. The crude HPV DNA prevalence was $10.7 \%$. Unlike most populations studied so far, HPV prevalence was high not only among young women, but also in middle and old age. Independent HPV determinants were being illiterate (prevalence odds ratio [POR], 13.9; 95\% confidence interval $[95 \% \mathrm{CI}], 1.9-100)$ and reporting more than three lifetime sexual partners (POR, 4.6; 95\% CI, 1.0-22.2).

Conclusions: The study indicates a high crude prevalence of HPV in a largely polygamous Ghanaian population with a high crude prevalence in older age groups, which may be a distinctive feature of polygamous populations where HPV transmission continues into middle age and cervical cancer incidence is very high.
\end{abstract}

Keywords: HPV, Prevalence, PCR, Ghana

\section{INTRODUCTION}

Human papillomaviruses (HPVs) are aetiological agents of cervical intraepithelial neoplasia and cervical cancer. Cervical cancer claims the lives of an estimated 231,000 women annually, with over $80 \%$ of these deaths occurring in developing countries. Cervical cancer is the most common female malignancy in subSaharan Africa. ${ }^{1}$ The incidence of cervical cancer in sub-Saharan Africa is among the highest worldwide, with the available age-standardised rates ranging from 19.9 per 100,000 in Ibadan, Nigeria, ${ }^{1}$ through 35.7 per 100,000 in Bamako, Mali, to 41.7 per 100,000 in Kyadondo, Ugandan. ${ }^{2}$ The prevalence of cervical HPV infection varies greatly worldwide. Population-based HPV prevalence surveys have shown a 13 -fold variation in sexually-active women aged 15-65 years, ranging from $2.0 \%$ in Hanoi, North Vietnam, ${ }^{3} 3.0 \%$ in Barcelona, Spain, ${ }^{4} 14.8 \%$ in Bogota, Columbia, ${ }^{5}$ through $17.7 \%$ in Concordia, Argentina, ${ }^{6}$ to the highest of $26.3 \%$ in Ibadan, Nigeria, ${ }^{7}$ a West African neighbour of Ghana.

Genital HPVs are common sexually transmitted viruses and the high-risk types (HR-HPV) have been shown to be the cause of invasive cervical cancer and its cytological precursors, squamous intraepithelial lesions. ${ }^{8-10}$ Additionally, the prevalence of HR-HPV types in middle-aged women and the incidence of cervical cancer in the same age group are strongly positively correlated. ${ }^{11}$ The prevalence of genital HPV is also directly related to the number of lifetime sexual partners, recent change in sexual partners, marital status, illiteracy, oral contraceptive use, alcoholism, smoking, hormonal and dietary factors, and immunosuppression. ${ }^{7,12-14}$ HPV 16 is the most common HPV type found in the cervix and in cervical cancers, where it is detected in over $50 \%$ of cases. The other types detected commonly in cervical cancers include types 18,45 and $31 .^{15}$ 
Recently available information on the prevalence of cervical HPV infection in subsets of the sexually-active female population in sub-Saharan Africa ${ }^{16-26}$ show comparably high prevalence rates to that found in the population-based survey in Nigeria, ${ }^{7}$ with some variations based on the sample selection and the type of HPV testing employed. Organized cytology screening programs have reduced the incidence of and mortality from cervical carcinoma in many developed countries, but the Papanicoloau (Pap) screening test is not available routinely in sub-Saharan Africa. Because cytological or HPV screening programs based on frequently repeated screening rounds would be expensive, logistically difficult and not feasible in many developing countries, immunization against HR-HPV offers the greatest hope for a long-term solution to cervical cancer. In the short-term, though, early detection of cervical neoplasia with visual inspection with acetic acid (VIA), now considered as a low-technology alternative to cervical cytology, is currently being evaluated in Ghana and other developing countries. ${ }^{27}$

The understanding of the behavioural characteristics that relate to the acquisition of HPV infections is important to identify subgroups within a population that are at higher risk for invasive cervical cancer. Using dot blot to detect the presence of HPV DNA, the evidence of cervical HPV infection was reported in 33\% and $48 \%$ of rural and urban women in Ghana, respectively. ${ }^{28}$ Here, we report the first PCR-based molecular study of cervical HPV infection in Ghana, and its correlates to the socio-demographic and reproductive characteristics of Ghanaian women.

\section{SUBJECTS AND METHODS}

\section{Study area and subjects}

This study was conducted at the Gynecology Outpatient Clinic of the Korle-Bu Teaching Hospital (KBTH), Accra, Ghana, between January and April 2002. KBTH, situated in the nation's capital, Accra, is the leading tertiary hospital and the major referral center in the country. Hence, most of the patients seen at KBTH are referral cases from various parts of Southern Ghana. It also serves as the teaching hospital of the University of Ghana Medical School. Thus the demographics of the patients that were tested in this study were not limited to a specific social group, such as commercial sex workers, who are expected to attend Gynaecological clinics more frequently. The patients in this study originated from various social and ethnic groups as well as geographically distinct areas from the vast territory of the Greater Accra region and the Southern part of Ghana. There was no selection of patients from a larger cohort of HPV-tested cases; the cases presented here were the first 75 consecutive pa- tients to enter the Gynaecology Clinic who consented to participate in the study and a request for HPV testing. The inclusion criteria required a patient's consent to take part in the study and the consented patient should not have any form of vaginal bleeding or discharge at the time of the study. Eighteen patients fulfilling the above inclusion criteria declined participation before we accrued our desired sample size of 75 , and the major reason offered was their lack of familiarity with the Papanicoloau test procedure on account of no previous history of Pap testing. The protocol for the study was approved by the Ethical and Protocol Review Committee of the University of Ghana Medical School.

\section{Questionnaire}

After an explanation of the study to each patient at their appropriate level of literacy, and following written informed consent, information was obtained from each consenting participant through personal interviews using structured questionnaire (including when necessary translation of the purpose, written informed consent form and the questionnaire of the study into local Ghanaian languages) assessing sociodemographic characteristics, sexual history, knowledge about cervical cancer, gynecological history as it relates to the risk factors associated with HPV infections.

\section{Sample collection and DNA Extraction}

Following completion of the questionnaire by personal interview, a consultant gynaecologist performed a gynaecological examination. After the examination, ectocervical and endocervical samples were obtained (from each patient) for the extraction of DNA for the detection of HPV. Briefly, a sterile vaginal speculum was inserted into the vagina of the patient, and using a sterile Ayre's spatula, exfoliated cells were obtained from the transformation zone of the cervix. The spatula was then rinsed in sterile phosphate buffer (PBS, $\mathrm{pH} 7.4$ ), centrifuged $(2,000 \mathrm{~g}, 5 \mathrm{~min})$, and the supernatant discarded. The pellets were placed in a microcentrifuge tube with $50 \mu$ l of lysing buffer solution containing $2.5 \mathrm{mM} \mathrm{MgCl}_{2}, 50 \mathrm{mM} \mathrm{KCl}, 10 \mathrm{mM}$ Tris $\mathrm{HCl}, \mathrm{pH} 8.3$, and $0.5 \%$ Tween 20. Two microliters of proteinase K (QIAGEN, GmbH, Germany) was also added and the mixture incubated at $56^{\circ} \mathrm{C}$ for 2 hours. The samples were spun $(2,000 \mathrm{~g}, 2 \mathrm{~min})$ briefly, and then incubated $\left(95^{\circ} \mathrm{C}\right.$ for 10 minutes $)$ to denature the residual protease. The digested samples were centrifuged at $2,000 \mathrm{~g}$, for 2 minutes and $5 \mu \mathrm{l}$ of the supernatant of each sample was used directly, without purification, as DNA template for PCR amplification.

\section{PCR Primers and Amplification}

To analyze the quality of target DNA for PCR testing, $5 \mu l$ of the supernatant of each of the 75 samples were 
screened with $\beta$-globin gene-specific control primers $(\mathrm{M} 24191),{ }^{29}$ and all 75 samples produced a positive $\beta$ globin result. General consensus primers GP5+ (5'TTTGTTGTGGTAGATACTC 3') and

GP6+ (5'GAAAAATAAACTGTAAATCATATTC 3') were used (Invitrogen Life Technologies, Frederick, MD, U.S.A). Amplification reactions were done using $5 \mu 1$ of DNA $(0.5 \%$ to $2 \%$ of the total extractable DNA) as DNA template, in a $50 \mu 1$ reaction mixture containing $50 \mathrm{mM} \mathrm{KCl}, 10 \mathrm{mM}$ Tris $\mathrm{HCl}(\mathrm{pH}$ 8.8), 3.6 $\mathrm{mM}, 0.1 \mathrm{mg} \mathrm{BSA} / \mathrm{ml}, 2.5 \mu \mathrm{l}$ deoxynucleoside triphosphate, and IU of Taq polymerase (QIAGEN). Fifty picomoles of each primer were used for the ultrasensitive amplification as previously described. ${ }^{30,31} \mathrm{HPV}$ negative control samples (K562 human DNA cell line DNA) were interspersed between clinical specimens to evaluate potential inter-specimen contamination. Positive control samples (HPV positive cell line CaSki cells, 600 viral copies of HPV DNA/cell) were interspersed between clinical specimens to monitor the overall amplification and hybridization process. The negative and positive control specimens were processed with all clinical specimens and each individual hybridization reaction tray contained at least 1 positive and 1 negative control.

\section{PCR Product Visualization}

Amplified DNA fragments were separated in 2\% agarose gel by electrophoresis and stained with ethidium bromide $(0.5 \mathrm{mg} / \mathrm{ml})$. The UV-illuminated gels were photographed with Kodak (type DC265, Epson, Suwa, Japan) digital camera. Electrophoresis was read by comparison with the DNA molecular weight ladder/markers, and a positive result was identified by corresponding to the $140 \mathrm{bp}$ fragment of the amplified HPV positive control sample (HPV positive cell line CaSki cells).

\section{Data Analysis}

The Statistical Analysis System (SAS Institute, Cary, NC) version 9.1 was used to complete all data analyses. The categories of some of the characteristics were combined into only two groups to avoid large confidence intervals, on account of our small study population size. The women were divided into 2 categories of age; less than or equal to 30 years and greater than 30 years. Educational levels were classified as illiterate or better; contraceptive use as barrier or non barrier; age at first sexual intercourse was divided into less than or equal to 18 years and greater than 18 years; number of life time partners as less than or equal to 3 and more than 3.In the univariate analysis, the frequencies for each of the variables above were calculated. The means, median, maximum and minimum values for age, age at first sexual intercourse and number of lifetime sexual partners were determined. The univariate analysis of age was repeated after having stratified by serum analysis results and compared the mean ages for statistically significant difference using the Student's T Test. In the bivariate analysis, odds ratios for HPV positivity and corresponding 95\% confidence intervals were calculated by means of unconditional, multiple logistic regression equations adjusted for age (continuous variable).

\section{RESULTS}

The 75 study participants had a mean age of 33.3 years (standard deviation, 9.2 years; range, 19 to 57 years). The vast majority $(90.7 \%)$ had at least primary level of education and $9.3 \%$ were illiterates. The majority $(85.3 \%)$ were married (with $16.4 \%$ in a polygamous marriage) and $14.7 \%$ were single, divorced or widowed. Fifty $(66.7 \%)$ had their first sexual intercourse by age 18 , with the earliest age being 14 years. The percentage of lifetime monogamy was $21.3 \%$, with $78.7 \%$ of the study participants having had 2 or more lifetime sexual partners. Their mean number of lifetime sexual partners was 2.5 , with the maximum number being 6 . Sixty-seven $(89.3 \%)$ had never used a female condom, whereas only $8(10.7 \%)$ had ever used a condom. Fifty-six percent (42 out of 75) had heard of cervical cancer, but only one study participant knew it is caused by HPV infection. Of the 42 study participants who had heard of cervical cancer, $20(47.6 \%)$ knew that it could be prevented but only one study participant knew that it could be prevented specifically by performing the Pap smear test. Thirty-four (45.3\%), 24 $(32.0 \%)$, and $4(5.3 \%)$ respectively, had histories of pelvic pain, offensive vaginal discharge and genital warts.

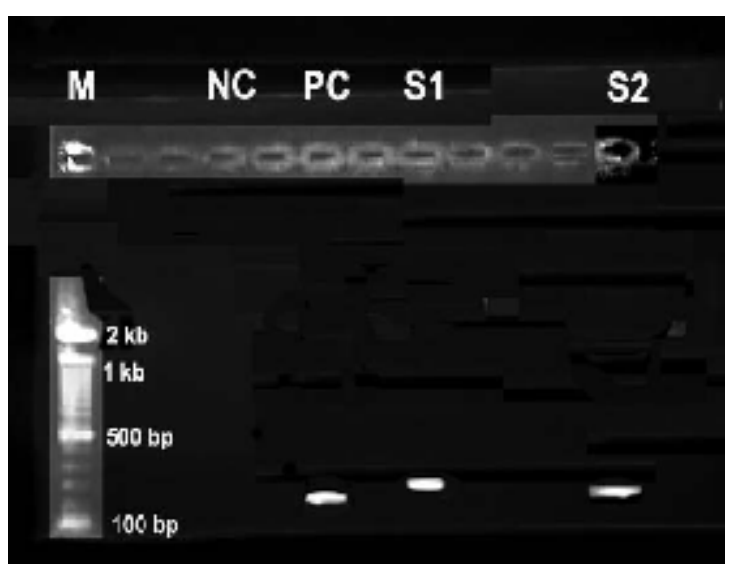

Figure 1 Gel photograph of simple Human Papillomavirus PCR products. The $140 \mathrm{bp}$ fragment corresponds to the amplified HPV DNA. Lane M: 100bp DNA molecular weight marker; NC: negative control (no DNA); PC: positive control 
(HPV positive cell line CaSki cells); S1 and S2: HPV DNA positive samples 1 and 2 , respectively.

Figure 1 shows the $2 \%$ agarose gel electrophoresis photograph of the products of the simple PCR amplification of the HPV DNA in the cervical scrapes. General consensus primers GP5+ and GP6+ were used to amplify the HPV L1 gene region of the HPV DNA. This synthesizes a $140 \mathrm{bp}$ fragment. Of the 75 cervical scrapes, positive HPV DNA PCR amplification was achieved in 8 , giving a crude HPV DNA prevalence of $10.7 \%$. DNA from these 8 specimens gave bands in the region of $140 \mathrm{bp}$, suggesting that the correct regions of the HPV DNA has been amplified and confirming the presence of HPV infection in these patients. The prevalence of HPV was highest (18.2\%) among women 4150 years of age, followed by $10.7 \%$ in $21-30$ year group, then $10 \%$ in $31-40$ year group, and $0 \%$ in $11-$ 21 and 51-60 year groups. The mean age of the $8 \mathrm{HPV}$ DNA positive women was 30.5 years (standard deviation, 9.1 years; range, 22 to 46 years), whilst the mean age of the 67 HPV DNA negative women was 33.6 years (standard deviation, 9.2 years; range, 19 to 57 years). There was no statistically significant difference ( $\mathrm{T}$ test, $\mathrm{t}=0.91, \mathrm{p}=0.4>0.05$ ) between the mean ages of the HPD DNA positive and negative women.

Table 1 shows the odds ratios (ORs) for HPV DNA positive detection and corresponding $95 \%$ confidence intervals (95\%CIs) according to the sociodemographic and reproductive behavioural characteristics among 75 women in Accra, Ghana. Illiteracy, which was reported by $9.3 \%$ of women, was associated with a OR for HPV DNA detection of 13.9 (95\%CI, $1.9-100)$. Women reporting more than 3 lifetime sexual partners, who accounted for $20 \%$ of our study participants, had 4.6-fold (95\%CI, 1.0 - 22.2) higher HPV DNA prevalence as compared with women reporting 3 or less lifetime sexual partners. Women older than 30 years, who accounted for $57.3 \%$ of our study participants, were at an increased risk (OR, 2.1; 95\% CI, 0.5 - 9.3) of HPV DNA detection as compared with women younger than 30 years, though the differences in prevalence estimates did not reach statistical significance. Sexual intercourse at 18 years of age or younger, reported by $66.7 \%$ of women, was associated with a OR for HPV DNA detection of $2.1(95 \% \mathrm{CI}, 0.4$ $-10.4)$, but differences did not reach the level of statistical significance. Condom use was not associated with HPV DNA detection (OR, 0.9; 95\%CI, 0.1 - 9.4).

\section{DISCUSSION}

The study group included women that were largely polygamous with multiple lifetime sexual partners, relatively early age at first sexual intercourse and very low lifetime use of condoms. This profile is consistent with the reported high incidence of cervical cancer in Ghana and other sub-Saharan African countries, ${ }^{1,2}$ and previous reports of high prevalence of cervical HPV infection in Ghana ${ }^{28}$ and other sub-Saharan African countries. ${ }^{7,16-24}$ The prevalence of HPV DNA detection of $10.7 \%$ found in women in Accra, Ghana is in the upper end of the world spectrum, ${ }^{3-7}$ and consistent with previous reports in women in sub-Saharan African.

Table 1: Odds Ratios (ORs) for Positive HPV DNA Detection and corresponding 95\% Confidence Intervals (95\% CIs) according to the sociodemographic and reproductive behavioural characteristics among 75 women in Accra, Ghana

\begin{tabular}{|c|c|c|c|}
\hline \multirow[t]{2}{*}{${ }^{\text {a }}$ Characteristic } & \multirow{2}{*}{$\begin{array}{c}\text { Number } \\
\text { of } \\
\text { Women }\end{array}$} & \multicolumn{2}{|c|}{$\begin{array}{c}\text { Positive HPV DNA De- } \\
\text { tection }\end{array}$} \\
\hline & & $\begin{array}{c}\text { Number } \\
(\%)\end{array}$ & $\begin{array}{c}{ }^{b} \mathrm{OR} \\
(95 \% \mathrm{CI})\end{array}$ \\
\hline \multicolumn{4}{|l|}{ Age (years) } \\
\hline$\leq \mathbf{3 0}$ & 34 & $3(8.8)$ & 1 \\
\hline$>\mathbf{3 0}$ & 41 & $5(12.2)$ & $\begin{array}{c}2.1 \\
(0.5-9.3)\end{array}$ \\
\hline \multicolumn{4}{|c|}{ Age at first sexual intercourse (years) } \\
\hline$\leq 18$ & 50 & $6(12.0)$ & $\begin{array}{c}2.1 \\
(0.4-10.4)\end{array}$ \\
\hline$>18$ & 25 & $2(8.0)$ & 1 \\
\hline \multicolumn{4}{|c|}{ Formal educational level achieved } \\
\hline $\begin{array}{c}\text { Primary or } \\
\text { Better }\end{array}$ & 68 & $5(7.4)$ & 1 \\
\hline $\begin{array}{l}\text { Illiterate or } \\
\text { None }\end{array}$ & 7 & $4(57.1)$ & $\begin{array}{c}13.9 \\
(1.9-100)\end{array}$ \\
\hline \multicolumn{4}{|c|}{ Condom (male \& female types) use } \\
\hline Never & 67 & $7(10.4)$ & $\begin{array}{c}0.9 \\
(0.1-9.4)\end{array}$ \\
\hline Ever & 8 & $1(12.5)$ & 1 \\
\hline \multicolumn{4}{|c|}{ Number of lifetime sexual partners } \\
\hline$\leq \mathbf{3}$ & 60 & $4(6.7)$ & 1 \\
\hline$>3$ & 15 & $4(26.7)$ & $\begin{array}{c}4.6 \\
(1.0-22.2)\end{array}$ \\
\hline
\end{tabular}

${ }^{a}$ Combined into only two categories to minimize the width of confidence intervals.

${ }^{\mathrm{b}}$ Adjusted for age.

Previous cervical HPV prevalence studies in subSaharan Africa have generally shown relatively high prevalence with some variations, based on the sample selection and the type of HPV testing employed. Polymerase chain reaction (PCR)-based assays, similar to 
that employed in this study, showed HPV prevalence of $44 \%$ in Nairobi, Kenya, ${ }^{24} 40 \%$ in rural Mozambique, ${ }^{18}$ $34 \%$ in Northwestern Tanzania, ${ }^{19,23} 31 \%$ in Harare, Zimbabwe, ${ }^{20} 26.3 \%$ in Ibadan, Nigeria, ${ }^{7} 18 \%$ in Dakar and Pikene, Senegal, ${ }^{22}$ and $15.4 \%$ in South Africa. ${ }^{21}$ The hybrid capture assay II showed HPV prevalence of $25 \%$ in Harare, Zimbabwe, ${ }^{17}$ and $17 \%$ in rural Uganda. ${ }^{16}$ Using dot blot to detect the presence of HPV DNA, the evidence of cervical HPV infection was previously reported in $33 \%$ and $48 \%$ of rural and urban women in Ghana, respectively, ${ }^{28}$ compared to the $10.7 \%$ herein reported using the more specific PCRbased assay.

The reported age pattern of HPV prevalence differs from one country to another, but the predominant reported pattern shows an early peak in the young age groups, soon after the start of sexual intercourse, ${ }^{32}$ followed by a steady decline in middle age, after clearance of a large proportion of newly acquired infections, and a steady state in the age group 40 and above. . $^{3,32,33}$ In some populations, U-shaped curves, with a second peak in postmenopausal women, were found, and this observation has generally been detected in countries with high incidence rates of cervical cancer. ${ }^{32-35}$ In three previous studies from sub-Saharan Africa, ${ }^{16,18,24}$ the prevalence of HPV declined significantly with age.

In two other sub-Saharan African studies, ${ }^{7,22}$ HPV prevalence showed no significant decline with age, and indeed, in one of these two studies ${ }^{22}$ high-risk, and not low-risk HPV types, were more frequently detected in older than younger women. The age-specific point prevalence of cervical HPV infection of the study group was notable, with a peak among women 41-50 years of age, followed by women in 21-30 year group, then women in 31-40 year group, and finally women in 11-21 and 51-60 year groups. The age pattern of HPV prevalence of the study group was U-shaped, with a higher second peak, and consistent with the general observation in countries with high cervical cancer incidence rates like Ghana. ${ }^{36}$ In Ghana, cervical cancer is the third most common cause of cancer mortality in women, accounting for $8.47 \%$ of cancer deaths in Ghanaian women. ${ }^{36}$ Additionally, the age pattern of HPV prevalence of the study group showed a general increase, there was no statistically significant differences in the age-specific rates of HPV DNA detection in the study women aged 30 and older compared to the study women younger than 30 years of age (Table 1). The explanations for the persistent high prevalence of HPV in middle and older aged women, and the peak HPV prevalence in the 41-50 year group (peri- and postmenopausal women) in Accra, Ghana are not obvious from this study. HPV prevalence age pattern similar to that of the study group in Accra, Ghana has previously been reported in two populations as very high-risk for cervical cancer, namely Chennai, Southern India ${ }^{18}$ and Ibadan, Nigeria. ${ }^{7}$ Hormonal changes as well as changes in sexual behaviour among peri- and post-menopausal women and their partners might both contribute to this observation. Specifically, in the Ghanaian and Nigerian societies where polygamy is generally accepted, a fraction of men and women (mainly men) may continue to have multiple sexual partners throughout their life and therefore reinfect themselves and their spouses. Additionally, as previously suggested, ${ }^{7}$ women in developing countries, like Ghana, Nigeria and India, may have decreased ability to clear HPV infections, possibly due to concomitant genital infections or nutritional deficiencies, since the development of an efficient immune response against HPV acquired over age is the generally accepted reason for the decline in HPV prevalence observed in other populations. ${ }^{3-6,32}$ The group of women who remain persistent carriers of HPV by middle age are now considered the high-risk group for cervical cancer. ${ }^{3-7,32-35}$

Being illiterate and reporting more than 3 lifetime sexual partners were the main correlates of HPV DNA detection among the study women. This confirms the findings of previous studies that demonstrated that the number of lifetime sexual partners ${ }^{4,14}$ and illiteracy ${ }^{7}$ are significantly associated with HPV infection. The previously identified barriers to the early detection of cervical cancer in Ghana were the low level of knowledge about cervical cancer etiology, pap smear test and cervical cancer screening. ${ }^{37}$ These barriers were confirmed in this study group, with the knowledge about cervical cancer, its' causes and prevention being very poor. This poses a tremendous health education challenge, since majority of the women studied are not even aware of the disease and the steps to prevent it from occurring. Therefore, increasing the proportion of population with formal education as well as intensifying health education would be necessary to reduce the prevalence of HPV infection and the incidence of cervical cancer in Ghana. Adolescents who have not yet had sexual intercourse should be educated, counseled and encouraged to postpone sexual initiation as long as possible. The general public should be educated on cervical cancer aetiology, the pap smear test and cervical cancer screening, and the importance of limiting the number of sexual partners and choosing sexual partners who have not themselves had multiple sexual partners.

Female condom use and delayed onset of sexual intercourse by the study group were not protective against HPV infection, and therefore the previously reported protective effect of condom use $\mathrm{u}^{3,4,12,14}$ and delayed onset of sexual intercourse ${ }^{14}$ against HPV infection could not be confirmed. This may be due to the small 
sample size of the study group. Despite combining some of the characteristics of our study participants into only two categories for the univariate and bivariate analysis, the relatively wide confidence intervals above is due to our small sample size. Additionally, our sample of 75 women may not be representative of the general Ghanaian population on account of the small sample size and the convenient sampling method employed.

\section{CONCLUSION}

In conclusion, this study suggests a high prevalence of HPV infection in some age groups of the largely polygamous Ghanaian female population as in other subSaharan African countries, and that the initiation of sexual intercourse before age 18 and illiteracy are associated with HPV infection. This has implications for extending the reach of formal education and for the design of adolescent-specific cervical cancer health educational programs in Ghana. However, the findings and conclusions of this study are limited by the small sample size of participants, and a much larger population-based study would be required to validate our findings.

\section{ACKNOWLEDGEMENTS}

This study was funded by a research grant from the Unilever (Ghana) Education and Research Trust Fund, Accra, Ghana, to Professor Edwin K. Wiredu and Professor Andrew A. Adjei.

\section{REFERENCES}

1. Parkin D.M., Ferlay J., Hamdi-Cherif M., Sitas F., Thomas J.O., Wabinga H. and Whelan S.L. Cancer in Africa: Epidemiology and Prevention. 4.3 Cervix Cancer. IARC Scientific Publications 2003; No 153: Lyon: IARC Press, pp 268-276.

2. Parkin D.M., Whelan S.L., Ferlay J., Thomas D.B. and Teppo L. Cancer Incidence in Five Continents. IARC Scientific Publications 2002; No 155: Lyon: IARC Press.

3. Anh P.T., Hieu N.T., Herrero R., Vaccarella S., Smith J.S., Thuy N.T., Nga N.H., Duc N.B., Ashley R., Snijders P.J., Meijer C.J., Munoz N., Parkin D.M. and Franceschi S. Human papillomavirus infection among women in South and North Vietnam. Int J Cancer 2003; 104: 213-220.

4. de Sanjose S., Almirall R., Lloveras B., Font R., Diaz M., Munoz N., Catala I., Meijer C.J., Snijders P.J., Herrero R. and Bosch F.X. Cervical human papillomavirus infection in the female population in Barcelona, Spain. Sex Transm Dis 2003; 30: 788-793.

5. Molano M., Posso H., Weiderpass E., van den Brule A.J., Ronderos M., Franceschi S., Meijer
C.J., Arslan A. and Munoz N. Prevalence and determinants of HPV infection among Colombian women with normal cytology. Br J Cancer 2002; 87: 324-333.

6. Matos E., Loria D., Amestoy G., Herrera L., Prince M.A., Moreno J., Krunfly C., van den Brule A.J., Meijer C.J., Munoz N., Herrero R. and Proyecto Concordia Collaborative Group. Prevalence of human papillomavirus (HPV) infection among women in Concordia, Argentina: a population-based study. Sex Transm Dis 2003; 30: 593599.

7. Thomas J.O., Herrero R., Omigbodun A.A., Ojemakinde K., Ajayi I.O., Fawole A., Oladepo O., Smith J.S., Arslan A., Munoz N., Snijders P.J.F., Meijer C.J.L.M. and Franceschi S. Prevalence of papillomavirus infection in women in Ibadan, Nigeria: a population based study. Br J Cancer 2004; 90: 638-645.

8. Walboomers J.M., Jacobs M.V., Manos M.M., Bosch F.X., Kummer J.A., Shah K.V., Snijders P.J., Peto J., Meijer C.J. and Munoz N. Human papillomavirus is a necessary cause of invasive cervical cancer worldwide. J Pathol 1999; 189:1219.

9. Bosch F.X., Lorincz A., Munoz N., Meijer C.J. and Shah K.V. The causal relation between human papillomavirus and cervical cancer. J Clin Pathol 2002; 55: 244-265.

10. Munoz N., Bosch F.X., de Sanjose S., Herrero R., Castellsague X., Shah K.V., Snijders P.J. and Meijer C.J. Epidemiologic classification of human papillomavirus types associated with cervical cancer. $N$ Engl J Med 2003; 348: 518-527.

11. Franceschi S., Rajkumar T., Vaccarella S., Gajalakshmi V., Sharmila A., Snijders P.J., Munoz N., Meijer C.J. and Herrero R. Human papillomavirus and risk factors for cervical cancer in Chennai, India: a case-control study. Int $J$ Cancer 2003; 107: 127-133.

12. Melamed M.R., Koss L.G., Flehinger B.J., Kelisky R.P. and Dubrow H. Prevalence rates of uterine cervical carcinoma in situ for women using the diaphragm or oral contraceptive steroids. $\mathrm{Br}$ Med $J$ 1969; 3: 195-200.

13. Alloub M.I., Barr B.B., McLaren K.M., Smith I.W., Bunney M.H. and Smart G.E. Human papillomavirus infection and cervical intraepithelial neoplasia in women with renal allografts. $\mathrm{Br} \mathrm{Med}$ $J$ 1989; 298: 153-156.

14. Scheinder A. and Koutski L.A. Natural history and epidemiologic features of genital human papillomavirus infection. In: Munoz N., Bosch F.X., Shah K.V., eds. The epidemiology of human papillomavirus and cervical cancer. IARC Scientific 
Publication 1992; No. 119: Lyon: IARC Press, pp 25-52.

15. Bosch F.X., Manos M.M., Munoz N., Sherman M., Jansen A.M., Peto J., Schiffman M.H., Moreno V., Kurman R. and Shah K.V. Prevalence of human papillomavirus in cervical cancer: a worldwide perspective. International biological study on cervical cancer (IBSCC) Study Group. $J$ Natl Cancer Inst 1995; 87: 796-802.

16. Serwadda D., Wawer M.J., Shah K.V., Sewankambo N.K., Daniel R., Li C., Lorincz A., Meehan M.P., Wabwire-Mangen F. and Gray R.H. Use of a hybrid capture assay of self-collected vaginal swabs in rural Uganda for detection of human papillomavirus. J Infect Dis 1999; 180: 13161319.

17. Womack S.D., Chirenje Z.M., Gaffikin L., Blumenthal P.D., McGrath J.A., Chipato T., Ngwalle S., Munjoma M. and Shah K.V. HPV-based cervical cancer screening in a population at high risk for HIV infection. Int $J$ Cancer 2000; 85: 206210.

18. Castellsague X., Menendez C., Loscertales M.P., Kornegay J.R., dos Santos F., Gomez-Olive F.X., Lloveras B., Abarca N., Vaz N., Barreto A., Bosch F.X. and Alonso P. Human papillomavirus genotypes in rural Mozambique. Lancet 2001; 358: $1429-1430$

19. Mayaud P., Gill D.K., Weiss H.A., Uledi E., Kopwe L., Todd J., Ka-Gina G., Grosskurth H., Hayes R.J., Mabey D.C. and Lacey C.J. The interrelation of HIV, cervical human papillomavirus, and neoplasia among antenatal clinic attenders in Tanzania. Sex Transm Infect 2001; 77: 248-254.

20. Gravitt P.E., Kamath A.M., Gaffikin L., Chirenje Z.M., Womack S. and Shah K.V. Human papillomavirus genotype prevalence in high-grade squamous intraepithelial lesions and colposcopically normal women from Zimbabwe. Int J Cancer 2002; 100: 729-732.

21. Williamson A-L., Marais D., Passmore J-A. and Rybicki E. Human papillomavirus (HPV) infection in Southern Africa: prevalence, immunity, and vaccine prospects. IUBMB Life 2002; 53: 253-258.

22. Xi L.F., Toure P., Critchlow C.W., Hawes S.E., Dembele B., Sow P.S. and Kiviat N.B. Prevalence of specific types of human papillomavirus and cervical squamous intraepithelial lesions in consecutive, previously unscreened, West-African women over 35 years of age. Int J Cancer 2003; 103: 803-809.

23. Mayaud P., Weiss H.A., Lacey C.J.N., Gill D.K. and Mabey D.C.W. Genital human papillomavirus genotypes in Northwestern Tanzania. J Clin Microbiol 2003; 41: 4451-4453.
24. De Vuyst H., Steyaert S., Van Renterghem L., Claeys P., Muchiri L., Sitati S., Vansteelandt S., Quint W., Kleter B., Van Marck E. and Temmerman M. Distribution of human papillomavirus in a family planning population in Nairobi, Kenya. Sex Transm Dis 2003; 30: 137-142.

25. Didelot-Rousseau M-N., Nagot N., CostesMartineau V., Valles X., Ouedraogo A., Konate I., Weiss HA., Van de Perre P., Mayaud P., Segondy M, and for the Yerelon Study Group. Human papillomavirus genotype distribution and cervical squamous intraepithelial lesions among high-risk women with and without HIV-1 infection in Burkina Faso. Br J Cancer 2006; 95: 355-362.

26. Grainge M.J., Seth R., Guo L., Neal K.R., Coupland C., Vryenhoef P., Johnson J. and Jenkins D. Cervical human papillomavirus screening among older women. Emerg Infect Dis 2005; 11(11): 1680-1685.

27. Sankaranarayanan R., Budukh A.M. and Rajkumar R. Effective screening programmes for cervical cancer in low- and middle-income developing countries. Bulletin WHO 2001; 79: 954-962.

28. Szela E., Bachicha J., Miller D., Till M. and Wilson J.B. Schistomiasis and cervical cancer in Ghana. Int J Gynecol Obstet 1993; 42: 127-130.

29. Saiki R.K., Gelfand D.H., Stoffel S., Scharf S.J., Higuchi R., Horn G.T., Mullis K.B. and Erlich H.A. Primer-directed enzymatic amplification of DNA with a thermostable DNA polymerase. Science 1988; 239: 487-491

30. De Roda Husman A.M., Walboomers J.M.M., van den Brule A.J.C., Meijer C.J. and Snijders P.J. The use of general primers GP5 and GP6 elongated at their 3' ends with adjacent highly conserved sequences improves human papillomavirus detection by PCR. J Gen Virol 1995; 76: 1057-1062.

31. Jacobs M.V., Snijders P.J.F., van den Brule A.J.C., Helmerhorst T.J., Meijer C.J. and Walboomers J.M. A general primer GP5+/6(+)-mediated PCRenzyme immunoassay method for rapid detection of 14 high-risk and 6 low-risk human papillomavirus genotypes in cervical scrapings. J Clin Microbiol 1997; 35: 791-795.

32. Jacobs M.V., Walboomers J.M., Snijders P.J., Voorhorst F.J., Verheijen R.H., FransenDaalmeijer N. and Meijer C.J. Distribution of 37 mucosotropic HPV types in women with cytologically normal cervical smears: the age-related patterns for high-risk and low-risk types. Int J Cancer 2000; 87: 221-227.

33. Ng'andwe C., Lowe J.J., Richards P.J., Hause L., Wood C., Angeletti P.C. The distribution of sexually-transmitted Human Papillomaviruses in HIV positive and negative patients in Zambia, Africa. BMC Infect Dis 2007; 7: 77. 
34. Herrero R., Hildesheim A., Bratti C., Sherman M.E., Hutchinson M., Morales J., Balmaceda I., Greenberg M.D., Alfaro M., Burk R.D., Wacholder S., Plummer M. and Schiffman M. Population-based study of human papillomavirus infection and cervical neoplasia in rural Costa Rica. $J$ Natl Cancer Inst 2000; 92: 464-474.

35. Lazcano-Ponce E., Herrero R., Munoz N., Hernandez-Avila M., Salmeron J., Leyva A., Meijer C.J. and Walboomers J.M. High prevalence of human papillomavirus infection in Mexican males: comparative study of penile-urethral swabs and urine samples. Sex Transm Dis 2001; 28: 277-280.

36. Wiredu E. K. and Armah H. B. Cancer mortality patterns in Ghana: a 10-year review of autopsies and hospital mortality. BMC Public Health 2006; 6:159.

37. Adanu R.M.K. Cervical cancer knowledge and screening in Accra, Ghana. J Women's Health Gender-Based Med 2000; 11: 487-488. 